\title{
The Formation of Passive Layers on Zinc Based Platings
}

\author{
Ali Tuncay Ozyilmaz, ${ }^{1, *}$ Gul Ozyilmaz ${ }^{1}$ and Ismail Hakki Karahan ${ }^{2}$ \\ ${ }^{1}$ University of Mustafa Kemal, Faculty of Arts and Sciences, Department of Chemistry, 31000 Hatay-Turkey \\ ${ }^{2}$ University of Mustafa Kemal, Faculty of Arts and Sciences, Department of Physics, 31000 Hatay-Turkey \\ * Corresponding author: E-mail: atuncay@mku.edu.tr \\ Tel.: + 903262455845 fax: +903262455867
}

Received: 23-06-2016

\begin{abstract}
Zinc-iron $(\mathrm{ZnFe})$ and zinc-iron-cobalt $(\mathrm{ZnFeCo})$ platings were achieved on carbon steel applying $3 \mathrm{~mA}$ current values. Then, oxalate (OX) and tartrate (Tart) passive layers obtained in sodium oxalate and sodium tartrate medium were formed on carbon steel, $\mathrm{ZnFe}$ and $\mathrm{ZnFeCo}$ plated carbon steel. SEM images showed that the passive layers on CS, $\mathrm{CS} / \mathrm{ZnFe}$ and $\mathrm{CS} / \mathrm{ZnFeCo}$ electrodes exhibited different crystal structures. Corrosion tests revealed that the $\mathrm{ZnFeCo}$ particles provided a significant barrier efficiency on CS layer when compared with ZnFe alloy plating. Furthermore, OX layers on $\mathrm{ZnFe}$ and $\mathrm{ZnFeCo}$ plated carbon steel electrodes exhibited better physical barrier behavior on than those of Tart layers in longer periods
\end{abstract}

Keywords: Alloy coatings, zinc, EIS, electrodeposition, passivation, corrosion protection

\section{Introduction}

Zinc plating provides good protection to underlying iron based substrates. Generally metallic zinc plating provides cathodic protection as a sacrificial anode on the base metal. ${ }^{1,2}$ Recently, there has been increasing interest in the use of electrodeposited zinc alloys against corrosion. They have been considered as alternative material instead of zinc coating on iron and steel substrates. These alloy platings are usually a combination of zinc and an iron group' metal. $\mathrm{ZnFe}$ and $\mathrm{ZnFeCo}$ coatings have attracted considerable attention in the automotive industry, because they combine high corrosion resistance with excellent mechanical performance. In particular, because electrodeposited $\mathrm{ZnFe}$ alloy coatings possess several superior properties such as excellent paintability, good welding properties and good corrosion resistance. ${ }^{3-10}$ At the same time, zinc based coating surfaces are still coated with thin chromate or phosphate layers. There have been several studies on the application of chromatings and phosphate coatings to improve the corrosion resistance of certain coatings used in automotive industry, industrial pipes and household items. These coatings have wide range of applications due to their significant physical properties. ${ }^{11-13}$ However, they do not last for longer period of time and can be source of lead pollution. Consequently, the corrosion performances of $\mathrm{ZnFe}$ and $\mathrm{ZnFeCo}$ coatings have been improved by insoluble layers and subsequent organic coatings. ${ }^{14-15}$

On the other hand, conductive polymers have been an interesting subject of research. They are of primary importance in a wide variety of scientific and industrial sectors. Some of their important properties are electrical conductivity, electroactivity, electrochromism, environmental stability, chemical stability and corrosion inhibitive property. ${ }^{16-24}$ Yet, there is an oxidation phase of the substrate electrode prior to the electropolymerization process. This phase leads to the formation of a passive layer on the electrode surface. The dissolution of the substrates occurs in proper electrolyte medium, which is required to generate a suitable surface for the deposition of the conducting polymers. Camalet et al. ${ }^{25}$ obtained good results in corrosion protection of mild steel with polyaniline coating synthesized in oxalic acid, which leads to the formation of a passive layer on the carbon steel substrate. In our earlier work, ${ }^{26}$ it was found that the passivation of the $\mathrm{ZnCo}$ alloy surface was necessary for the homogenous polymer film synthesis prior to monomer oxidation and film growth.

In this study, passive layers were achieved electrochemically on carbon steel (CS), zinc-iron alloy plated car- 
bon steel $(\mathrm{CS} / \mathrm{ZnFe})$ and zinc-iron-cobalt alloy plated carbon steel $(\mathrm{CS} / \mathrm{ZnFeCo})$ in sodium oxalate $(\mathrm{NaOX})$ and sodium tartrate (NaTart) medium, in order to compare the properties of passive layers obtained in different electrolyte solutions. The synthesis of oxalate (OX) and tartrate (Tart) layers was obtained on $\mathrm{CS}, \mathrm{CS} / \mathrm{ZnFe}$ and $\mathrm{CS} / \mathrm{ZnFe}$ Co electrodes including an amount of them, which enhances the passivation process. The corrosion performance of $\mathrm{CS}, \mathrm{CS} / \mathrm{ZnFe}$ and $\mathrm{CS} / \mathrm{ZnFeCo}$ electrodes with and without $\mathrm{OX}$ or Tart layer was investigated in $3.5 \% \mathrm{NaCl}$ and compared with the AC impedance diagrams and anodic polarization curves.

\section{Materials and Methods}

Sodium oxalate and sodium tartrate solutions were prepared using distilled water and all experiments were carried out at room temperature open to the atmosphere. In this study, all electrochemical experiments were performed in a single compartment cell with three electrode configurations. The reference electrode was an $\mathrm{Ag}(\mathrm{s}) / \mathrm{Ag}-$ $\mathrm{Cl}(\mathrm{s}) / \mathrm{Cl}^{-1}(3 \mathrm{~mol} \mathrm{~L}-1, \mathrm{KCl})$ electrode and the counter electrode was a platinum sheet with a surface area of 0.36 $\mathrm{cm}^{2}$. A CHI 660B model digitally controlled electrochemical analyzer (serial number: A1420) was used in electrochemical experiments. All of the potential values were referred to the $\mathrm{Ag}(\mathrm{s}) / \mathrm{AgCl}(\mathrm{s}) / \mathrm{Cl}^{-1}\left(3 \mathrm{~mol} \mathrm{~L}^{-1}, \mathrm{KCl}\right)$ electrode. The working electrode was a carbon steel surface (MS) measuring $0.350 \mathrm{~cm}$ in diameter and with the following composition (wt\%): C (0.0561), Mn (0.4498), Si (0.1408), S (0.0036), P (0.0036) and Fe (balance). Carbon steel electrodes were embedded in a thick polyester block. In order to remove any existing passive film, the surface of working electrodes was polished with the help of grade emery paper up to 1200 prior to each experiment and before electrodeposition, rinsed in 1:1 ethanol acetone mixture, washed with bi-distilled water and subsequently dried.

Among the five different current values (1.0; 2.0; 3.0; 4.0 and $5.0 \mathrm{~mA}$ ) applied for electroplating, applying $3 \mathrm{~mA}$ current value which had highest corrosion performance, zinc-iron $(\mathrm{ZnFe})$ and zinc-iron-cobalt $(\mathrm{ZnFeCo})$ platings were successfully deposited on carbon steel (CS) with chronopotentiometry technique. $\mathrm{ZnFe}$ plating was carried out using a bath based on 23.14 zinc sulfate ( $\mathrm{Zn}$ $\left.\mathrm{SO}_{4}\right), 10.93$ iron (II) sulfate $\left(\mathrm{FeSO}_{4}\right), 24.97$ sodium citrate $\left(\mathrm{Na}_{3} \mathrm{C}_{6} \mathrm{H}_{5} \mathrm{O}\right), 15.98$ boric acid $\left(\mathrm{H}_{3} \mathrm{BO}_{3}\right), 24.97$ glycine by weight $\%$ at $\mathrm{pH} 4.0$. In case of and $\mathrm{ZnFeCo}$ plating, the composition of the bath was 40.90 zinc sulfate $\left(\mathrm{ZnSO}_{4}\right)$, 7.87 cobalt sulfate $\left(\mathrm{CoSO}_{4}\right), 2.78$ iron (II) sulfate $\left(\mathrm{FeSO}_{4}\right)$, 12.68 sodium citrate $\left(\mathrm{Na}_{3} \mathrm{C}_{6} \mathrm{H}_{5} \mathrm{O}\right), 12.68$ boric acid $\left(\mathrm{H}_{3} \mathrm{BO}_{3}\right), 22.84$ ammonium chloride $\left(\mathrm{NH}_{4} \mathrm{Cl}\right)$ and 0.25 sodium sulfate $\left(\mathrm{Na}_{2} \mathrm{SO}_{4}\right)$ by weight $\%$ at $\mathrm{pH}$ 5.0. The thickness of alloy platings was determined by estimation of the passing charge amount applying $3 \mathrm{~mA}$ constant current, while the thicknesses of $\mathrm{CS} / \mathrm{ZnFe}$ and $\mathrm{CS} / \mathrm{ZnFeCo}$ alloy platings were estimated to be between $3.45-4.45 \mu \mathrm{m}$ and 3.43-4.45 $\mu \mathrm{m}$, respectively. The counter electrode was a Pt sheet with $0.36 \mathrm{~cm}^{2}$ surface area and all alloy platings were obtained by unstirring the solution under atmospheric condition.

Oxalate and tartrate layers were synthesized by means of cyclic voltammetry technique. These layers obtained in the $0.20 \mathrm{M}$ sodium oxalate $(\mathrm{NaOX})$ or $0.20 \mathrm{M}$ sodium tartrate (NaTart) solutions were coated on $\mathrm{ZnFe}$ or $\mathrm{ZnFeCo}$ alloy deposited carbon steel electrode by applying a scan rate of $50 \mathrm{mV} \mathrm{s}^{-1}$. At $21^{\circ} \mathrm{C}$, the $\mathrm{pHs}$ of $\mathrm{NaOX}$ and NaTart solutions were 7.60 and 7.43 , respectively. Electrochemical impedance spectroscopy, anodic polarization curves, linear sweep voltammograms and open circuit potential- time curves were used to investigate the corrosion performance of the coatings. Using amplitude of $7 \mathrm{mV}$, Nyquist plots were recorded at instantaneous open circuit potentials for various exposure times and in the frequency range from $10^{5}$ to $10^{-3} \mathrm{~Hz}$. Scanning electron microscopy (SEM) was employed to characterize the surface morphology with JEOL JSM-5500LV Scanning electron microscope. The preferable orientations of the $\mathrm{ZnFe}$ and $\mathrm{ZnFeCo}$ deposits were determined by X-ray diffraction (XRD) analysis, with a Philips PANalytical $X$ 'Pert Pro X-ray diffractometer with $\mathrm{CuK}-\alpha$ radiation (lamda $=1.5418 \AA$ ). The 2 range of $20-60^{\circ}$ was recorded at the rate of $0.02^{\circ} 2 \theta / 0.5 \mathrm{~s}$. The crystal phases were identified comparing the 2 values and intensities.

\section{Results and Discussion}

\section{1. The Synthesis of Zinc-Iron ( $\mathrm{ZnFe})$ and Zinc-Iron-Cobalt (ZnFeCo) Platings}

Chronopotentiometry curves recorded for $\mathrm{ZnFe}$ and $\mathrm{ZnFeCo}$ platings obtained on carbon steel (CS) applying current of $3 \mathrm{~mA}$ in proper bath solution are given in Fig. 1a. Both platings were achieved in 300 seconds. The potential values obtained for $\mathrm{ZnFe}$ and $\mathrm{ZnFeCo}$ platings shifted to cathodic direction at 9.0 and 29.0 seconds. Then, the behavior of each plating baths exhibited almost constant potential value after shifting to anodic potential values in time. The cobalt presence of $\mathrm{CS} / \mathrm{ZnFeCo}$ electrode was proved by a significant potential shift towards nobler values, while there was a great difference between the plating potential values of $\mathrm{CS} / \mathrm{ZnFe}$ and $\mathrm{CS} / \mathrm{ZnFeCo}$ electrodes.

Linear sweep voltammograms recorded for CS, $\mathrm{CS} / \mathrm{ZnFe}$ and $\mathrm{CS} / \mathrm{ZnFeCo}$ electrodes in $0.05 \mathrm{M}$ EDTA containing $0.50 \mathrm{M}$ sodium sulfate solution are given in Fig. 1b. All measurements were taken at a scan rate of 5 $\mathrm{mV} \mathrm{s}^{-1}$. There was only single anodic dissolution peak for bare CS electrode and three anodic dissolution peaks for $\mathrm{CS} / \mathrm{ZnFe}$ and four anodic dissolution peaks for $\mathrm{CS} / \mathrm{ZnFe}$ - 

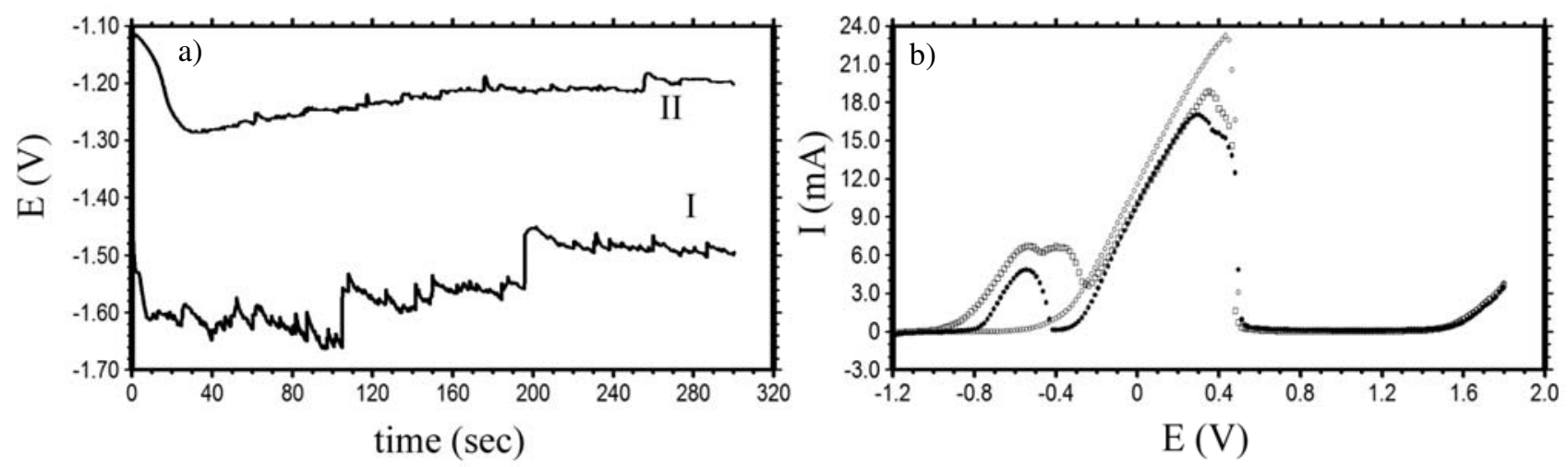

Fig. 1. The chronopotentiometric curves of $\mathrm{ZnFe}$ (I) and $\mathrm{ZnFeCo}$ (II) alloy plated electrodes in $3.5 \% \mathrm{NaCl}$ solution (a) and the anodic linear sweep voltammograms (ALSVs) of CS (O), $\mathrm{ZnFe}(\bullet)$ and $\mathrm{ZnFeCo}(\square)$ electrodes in $0.50 \mathrm{M} \mathrm{Na}_{2} \mathrm{SO}_{4}+0.05 \mathrm{M} \mathrm{EDTA}$ solution at scan rate $5 \mathrm{mV} \mathrm{s}{ }^{-1}$ at $23.0^{\circ} \mathrm{C}$, (b), immediately after of exposure time.

Co electrodes. The peaks observed at approx. $-0.54 \mathrm{~V}$ and $0.40 \mathrm{~V}$ for $\mathrm{CS} / \mathrm{ZnFe}$ electrode were due to dissolution of zinc and iron by formation of zinc and iron complex with EDTA, while the same peaks for CS electrode did not appear in this potential. On the other hand, different anodic dissolution peaks at approx. $-0.38 \mathrm{~V}$ for $\mathrm{CS} / \mathrm{ZnFeCo}$ electrode were attributed to the shift to negative potential values due to the regular structure of little iron plating in crystal structure. The single peak corresponding to the anodic dissolution of iron substrate was observed at approx. $+0.44 \mathrm{~V}^{27}$ On the other hand, there was an important difference between the heights of $\mathrm{ZnFe}$ and $\mathrm{ZnFeCo}$ alloy dissolution peaks and bare CS metallic dissolution, which could be related to the presence of alloy platings on the $\mathrm{CS}$ electrode. Dissolution peaks of $\mathrm{ZnFe}$ and $\mathrm{ZnFeCo}$ electrodes had low current intensities, corresponding to its significant barrier behavior against dissolution, while bare CS electrode exhibited high dissolution peak. It revealed that the $\mathrm{ZnFe}$ and $\mathrm{ZnFeCo}$ layers did not allow significant dissolution of CS electrode. Yet, the current values recorded for dissolution peaks were the lowest in presence of $\mathrm{ZnFe}$ plating. It was clear that, $\mathrm{ZnFe}$ and $\mathrm{ZnFeCo}$ layers provided an adequate physical protection between the base metal and corrosive environment. Consequently, zinc and cobalt oxide layers on $\mathrm{CS} / \mathrm{ZnFe}$ and $\mathrm{CS} / \mathrm{ZnFeCo}$ electrodes exhibited an efficient barrier property against the corrosive products.

Fig. 2Aa demonstrates a typical XRD pattern of the electrodeposited $\mathrm{ZnFe}$ alloy. The phases of the electrodeposited $\mathrm{ZnFe}$ alloy were very complicated depending on the chemical compositions. ${ }^{28-29}$ The reflections of zincrich phase (JCP: 4-0831) and a æ phase were present in all investigated deposits. The electrodeposited $\mathrm{ZnFe}$ alloys had metastable structures and many phases coexisted over a wide range of composition. Adaniya et al. reported that the phases of electrodeposited $\mathrm{ZnFe}$ alloys included: $\eta$ phase $(100-81 \% \mathrm{Zn}), \delta_{1} / \gamma$ phase $(89-70 \% \mathrm{Zn}), \gamma$ phase $(87-48 \% \mathrm{Zn})$ and $\alpha$ phase $(62-0 \% \mathrm{Zn}) .{ }^{30}$ Only relative intensities of the two phases changed among the deposited layers with different compositions. As the $\mathrm{Zn}$ content in the deposits increased, the signals belonging to the $\eta$ phase became more intense. Amirat et al. showed that iron incorporation leads to a dual phase alloy corresponding to a mixture of $\eta-\mathrm{Zn}$ and $\zeta-\mathrm{ZnFe}$ phases, at $10 \mathrm{~mA} \mathrm{~cm}{ }^{-2}$. For the higher electrolytic concentration of iron in the acidic chloride electrolytic bath $(\mathrm{Zn}(\mathrm{II}) / \mathrm{Fe}$ (II) concentration rate $=1 / 6$ ) the presence of $\zeta$-phase is highlighted. ${ }^{31}$ In presence of this study, current density and $\mathrm{Zn}$ (II)/Fe(II) concentration rate were attempted to be $7.8 \mathrm{~mA} \mathrm{~cm}^{-2}$ and 2 , respectively.

Fig. 2Ab shows XRD spectra for $\mathrm{ZnFeCo}$ coatings on carbon steel. The $\mathrm{Zn}$ reflection (101) was the highest of zinc, in $\mathrm{ZnFe}$ and $\mathrm{ZnFeCo}$ coating indicating preferred orientation of this phase. ${ }^{32}$ The pattern of the $\mathrm{ZnFeCo}$ coating was very different. The intensity of $\mathrm{Zn}$ (101) became the strongest. Winiarski ${ }^{33}$ illustrated that the XRD results of electroplating $\mathrm{ZnCo}$ alloy were in agreement with the results observed in this study. In addition, this structure change in alloy plating could be explained by the different appearance in SEM images (Fig. 2Bb). The intensity of the peak corresponding $\mathrm{Zn}$ (101) increased progressively in $\mathrm{ZnFeCo}$ alloy coatings. Thus, $\mathrm{X}$-ray diffraction study clearly indicates that a drastic change in the corrosion resistance of $\mathrm{ZnFeCo}$ coating was the consequence of change in the phase structures of the coatings. Fig. $2 \mathrm{Ba}$ and $\mathrm{b}$ shows the surface morphology of the $\mathrm{ZnFe}$ and $\mathrm{ZnFeCo}$ deposits as observed by SEM. This denoted a smooth granular deposit. As shown in Fig. 2Ba the morphology of the deposits in absence of cobalt content was small granular and more isotropic in shape. A smooth great granular uniform morphology was observed in $\mathrm{ZnFeCo}$ alloy deposit, which was due to the higher percentage of more noble metal in the deposit.

The synthesis of conducting polymers on oxidizable metal and their alloys have been reported in the literature recently. There is an oxidation phase of the substrate electrode prior to electropolymerization process. This phase leads to the formation of a passive layer on the electrode 

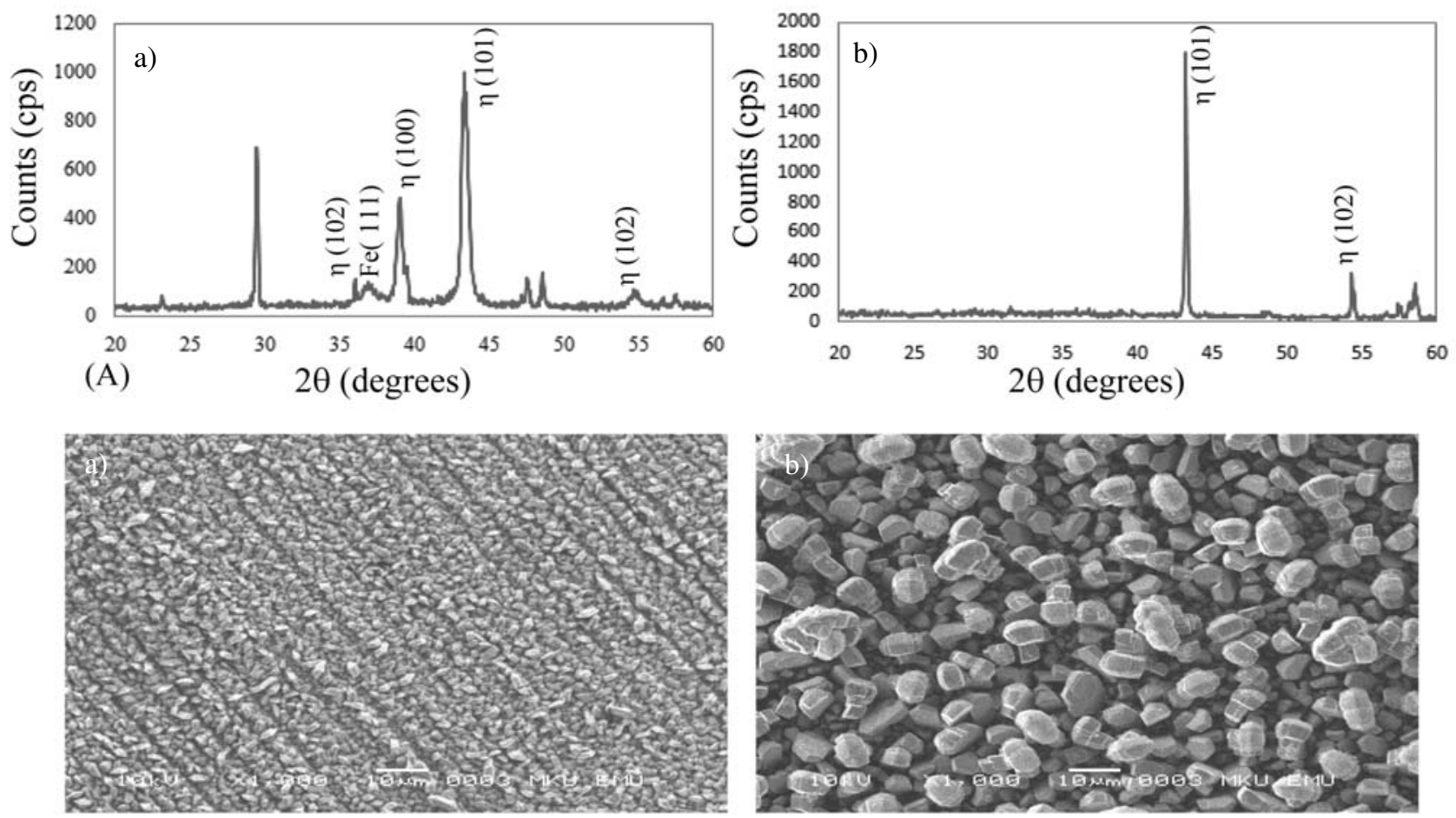

(B)

Fig. 2. X-ray diffractograms (A) and SEM images (magnification: 1000) (B) of ZnFe (a) and ZnFeCo (b) platings obtained on carbon steel applying constant current of $3 \mathrm{~mA}$.

surface. ${ }^{34}$ Passivation of especially carbon steel and iron prior to electropolymerization is very important in synthesizing homogenous and adherent polymer films. On the other hand, polymerization rate and polymer structure depend strongly on the anion type in the supporting electrolyte due to a different degree of specific adsorption of anions on mild and stainless steel. Hence, sodium oxalate and sodium tartrate aqueous solutions were used as an electrolyte to form a proper passive layer, in this study. The formulas of oxalate and tartrate anions are given below<smiles>O=C([O-])C(=O)[O-]</smiles>

oxalate ion<smiles>O=C([O-])[C@@H](O)[C@H](O)C(=O)[O-]</smiles>

tartrate ion
$\mathrm{NaOX}$ and NaTart solutions at different concentrations $(0.20 \mathrm{M} ; 0.10 \mathrm{M} ; 0.05 \mathrm{M}$ and $0.01 \mathrm{M})$ of were employed to obtain oxalate (OX) and tartrate (Tart) layers on $\mathrm{CS}$ and $\mathrm{CS} / \mathrm{ZnFe}$ and $\mathrm{CS} / \mathrm{ZnFeCo}$ electrodes. The $\mathrm{OX}$ and Tart layers formed by using an electrolyte solution at 0.20
$M$ exhibited better barrier results against the attack of corrosion products to $\mathrm{CS}, \mathrm{CS} / \mathrm{ZnFe}$ and $\mathrm{CS} / \mathrm{ZnFeCo}$ electrodes in $3.5 \% \mathrm{NaCl}$ solution. Therefore, all results in the present study were given for $0.20 \mathrm{M} \mathrm{NaOX}$ and $0.20 \mathrm{M}$ NaTart solutions.

In order to determine different processes occurring at the electrode surface, CS electrode was polarized in aqueous $\mathrm{NaOX}$ and NaTart solutions. Cyclic voltammograms recorded for $0.20 \mathrm{M} \mathrm{NaOX}$ and $0.20 \mathrm{M}$ NaTart solutions are given in Fig. 3.

All measurements were taken at a scan rate of $50 \mathrm{~m}$ $\mathrm{V} \mathrm{s}^{-1}$. Twenty whole cycles were applied to obtain the oxalate and tartrate layers on CS electrode. During the first positive cycle for both NaOX and NaTart media, anodic current values remained almost constant close to zero up to $1.20 \mathrm{~V}$. During the subsequent anodic potential, current values started to rise continuously due to transpassivation of CS electrode. The transpassivation potential of the CS electrode in NaTart solution shifted to negative values when compared with that of the $\mathrm{NaOX}$ solution. This denoted to poor interaction between carbon steel and tartrate ions due to the steric effect of hydroxide $(-\mathrm{OH})$ groups in tartrate ion with respect to oxalate ions. At the reverse scan, the sharp peaks, which appeared at around $-0.22 \mathrm{~V}$ recurred as the re-passivation peak for CS electrode. This peak was attributed to reduction from ferric compounds back to the ferrous compound on the surface. 

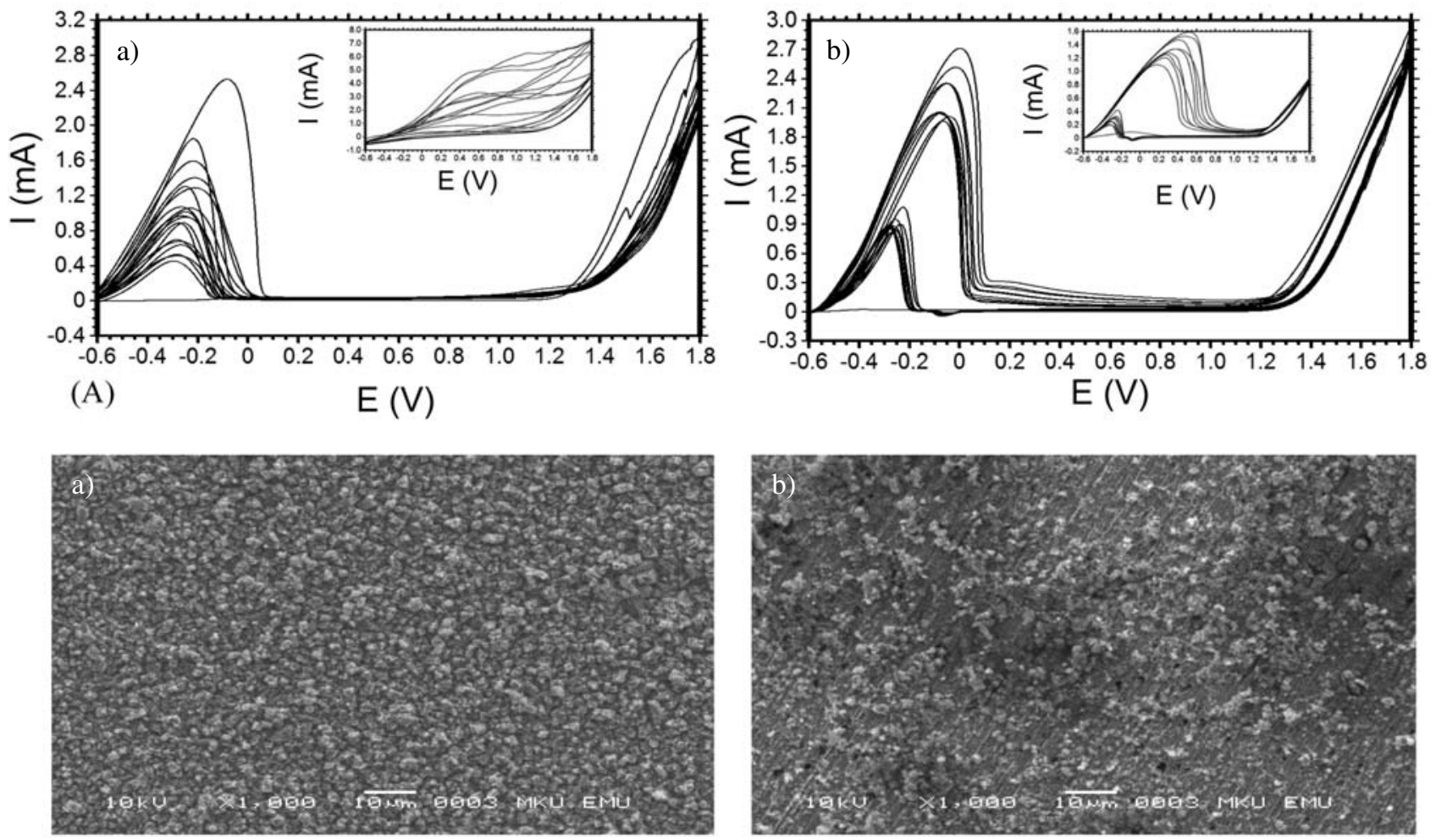

(B)

Fig. 3. Film growth curves (A) and SEM images (magnification: 1000) (B) of layers obtained on CS electrode in a) $0.20 \mathrm{M} \mathrm{NaOX} \mathrm{b)} 0.20 \mathrm{M}$ NaTart solution, scan rate: $50 \mathrm{mV} \mathrm{s}^{-1}$.

During second and following anodic cycles, the oxidation/passivation behavior of the CS electrode was observed as well defined peak.

The passivation mechanism was based on the formation of insoluble iron (II) oxalate or iron (II) tartrate precipitations on the CS electrode. During second anodic scan, the current value of oxidation/passivation peak obtained for oxalate medium were fairly higher when compared with that of tartrate medium. This case could be explained by the inhibiting effect of huge tartrate ions. After second anodic cycle for both conditions, current values corresponding to the oxidation/passivation peak for CS electrode were found to decrease regularly with increasing scanning numbers.

In order to determine different processes occurring at the $\mathrm{ZnFe}$ alloy plated carbon steel $(\mathrm{CS} / \mathrm{ZnFe})$ electrode surfaces, $\mathrm{CS} / \mathrm{ZnFe}$ electrode was polarized in aqueous NaOX and NaTart solutions which are referred to here as $\mathrm{CS} / \mathrm{ZnFeOX}$ and $\mathrm{CS} / \mathrm{ZnFeTart}$, respectively. In order to prevent the dissolution of zinc metal, OX and Tart layers on $\mathrm{CS} / \mathrm{ZnFe}$ electrode was achieved by cyclic voltammogram $(\mathrm{CV})$ within potential range -0.60 to $1.80 \mathrm{~V}$. CVs curves obtained in both mediums are given in Fig. 4. CVs recorded during oxalate and tartrate layer growths on $\mathrm{CS} / \mathrm{ZnFe}$ electrode were significantly different from that of CS electrode. On the other hand, CVs of first scan re- corded for $\mathrm{CS} / \mathrm{ZnFe}$ electrode in $\mathrm{NaOX}$ and NaTart solutions were significantly different, while the different behavior from bare CS electrode were obtained during anodic scans with various current values. During the first positive cycle in presence of $\mathrm{NaOX}$ solution, active dissolution of $\mathrm{CS} / \mathrm{ZnFe}$ electrode started at around $-0.60 \mathrm{~V}$, while the passivation of this electrode ended at around $0.51 \mathrm{~V}$. Then, anodic current values remained almost constant close to zero up to $1.27 \mathrm{~V}$. Anodic current values sharply started to rise due to transpassivation process and oxygen gas evolution. The first $\mathrm{CV}$ of $\mathrm{CS} / \mathrm{ZnFe}$ in NaTart solution exhibited completely different feature from the one recorded in $\mathrm{NaOX}$ solution up to the commencement of transpassivation process. The passivation of $\mathrm{CS} / \mathrm{ZnFe}$ electrode was observed in the narrow potential region while two oxidation/passivation peaks for $\mathrm{CS} / \mathrm{ZnFe}$ electrode in NaTart solution were well defined in potential domain between -0.60 and $0.52 \mathrm{~V}$. This revealed that the surface of the $\mathrm{CS} / \mathrm{ZnFe}$ electrode was active in the wide potential region. The current intensity of this potential region was significantly higher when compared with that of $\mathrm{NaOX}$ medium. At the reverse scan, a sharp peak, which appeared at around $-0.13 \mathrm{~V}$ was observed as the repassivation peak for $\mathrm{CS} / \mathrm{ZnFe}$ electrode in $\mathrm{NaOX}$ solution, while this event in NaTart solution appeared as a current wave in the wide potential region. 

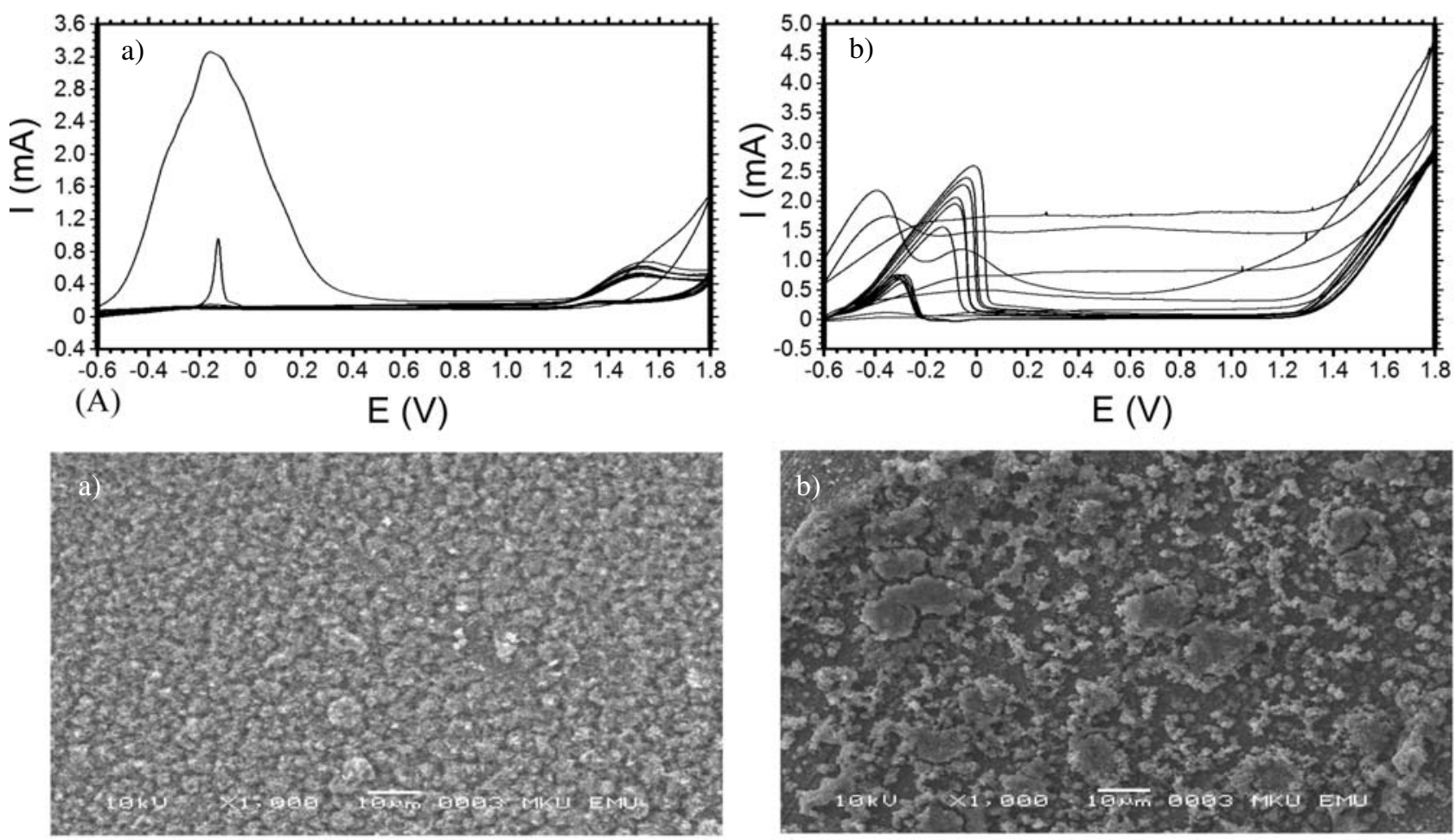

(B)

Fig. 4. Film growth curves (A) and SEM images (magnification: 1000) (B) of layers obtained on CS/ZnFe electrode in a) $0.20 \mathrm{M} \mathrm{NaOX} \mathrm{b)} 0.20 \mathrm{M}$ NaTart solution, scan rate: $50 \mathrm{mV} \mathrm{s}^{-1}$.
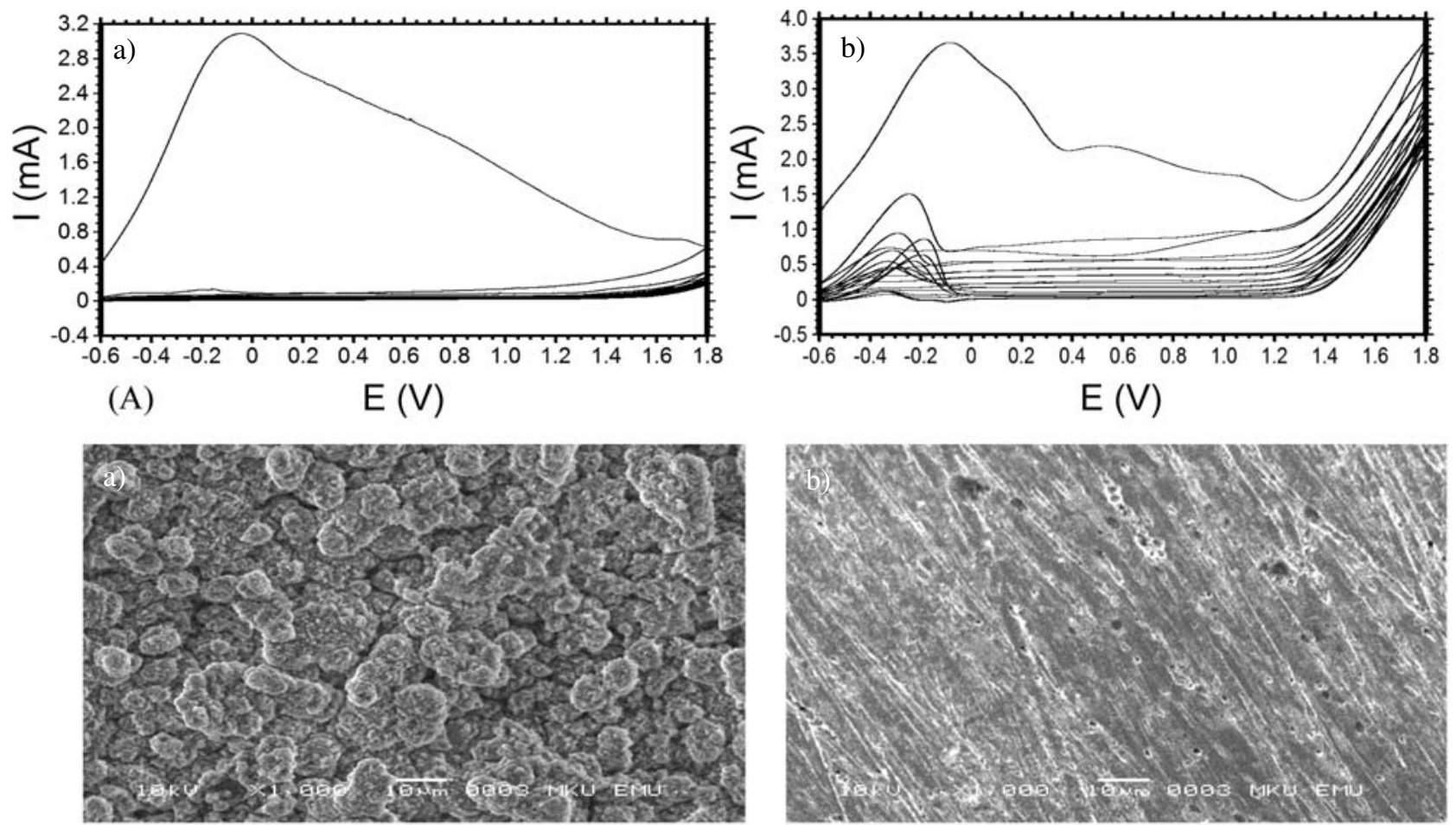

(B)

Fig. 5. Film growth curves (A) and SEM images (magnification: 1000) (B) of layers obtained on CS/ZnFeCo electrode in a) $0.20 \mathrm{M} \mathrm{NaOX}$ b) 0.20 $\mathrm{M}$ NaTart solution, scan rate: $50 \mathrm{mV} \mathrm{s}^{-1}$. 
This peak was attributed to reduction from ferric compounds back to the ferrous compound on the surface. However, this peak disappeared for $\mathrm{CS} / \mathrm{ZnFe}$ obtained in $\mathrm{NaOX}$ solution due to formation of insoluble zinc oxalate and zinc oxide mono hydrate layers instead of ferric compounds on electrode surface. During second and following scans, there was not any current increase for the oxidation/passivation and repassivation process of $\mathrm{CS} / \mathrm{ZnFe}$ electrode in $\mathrm{NaOX}$ solution, while they recurred as decreasing current values in NaTart solution.

Fig. 5 shows the cyclic voltammograms recorded for $\mathrm{CS} / \mathrm{ZnFeCo}$ electrode in $\mathrm{NaOX}$ and NaTart electrolyte solutions. In presence of $\mathrm{NaOX}$ solution, high current values obtained for the formation of iron oxalate and cobalt oxalate layers made it clear that passivation of $\mathrm{CS} / \mathrm{ZnFeCo}$ electrode ended during oxidation/passivation process, which could be explained by low current values which were observed during second and following scans. However, this passivation phenomenon could not be seen on the same CS/ZnFeCo electrode in NaTart solution. So, the intensities of both oxidation/passivation peaks at anodic scan and the repassivation peaks at cathodic scan were found to decrease steadily with increasing scanning numbers. After the second anodic scan, passive region was observed in the wide potential range before transpassivation process.

\section{3. Corrosion Performances of Uncoated and Coated Electrodes}

The anticorrosive properties of all electrodes were evaluated in the $3.5 \% \mathrm{NaCl}$ solution with anodic polariza- tion curves, the open circuit potential $\left(\mathrm{E}_{\mathrm{ocp}}\right)$-time curves and electrochemical impedance spectroscopy (EIS).

The Nyquist diagrams of CS, CS/ZnFe and CS/ZnFeCo electrodes recorded for 48 and $168 \mathrm{~h}$ of exposure times are given in Fig. 6.

Nyquist plots recorded for $\mathrm{CS}$ and $\mathrm{CS} / \mathrm{ZnFeCo}$ electrodes consisted of only one depressed semicircle, while two different constant phase elements were observed at region ranging from high frequency to low frequency for $\mathrm{CS} / \mathrm{ZnFe}$ electrode. The appearance of different constant phase elements indicated prominent differences between capacitive behavior of passive layers and the corrosion reaction on the $\mathrm{CS} / \mathrm{ZnFe}$ surface. Consequently, this suggested that two different constant phase elements were observed for metal/electrolyte and plating/electrolyte interfaces. After $48 \mathrm{~h}$ of immersion time, the corrosion rate $\left(\mathrm{I}_{\text {corr }}\right)$ of alloy platings was higher than bare carbon steel due to active zinc content (Table 1).

In Nyquist curves of all electrodes, the appearance of only one capacitive semicircle could be related to the insignificant phenomena revealing a change to activate carbon steel at the metal/solution interface, after $168 \mathrm{~h}$ of exposure time. This indicated smaller differences between capacitive behavior of passive layers and the corrosion reaction on the surface. Consequently, this suggested that the constant phase element might be considered as two overlapping semicircles. This behavior recorded for CS electrode was discussed in detail in our previous study. ${ }^{26}$

In Table 1 , The $\mathrm{R}_{\mathrm{p}}$ value decreased for CS electrode, while these values obtained for $\mathrm{CS} / \mathrm{ZnFe}$ and $\mathrm{CS} / \mathrm{ZnFeCo}$ electrodes increased after $168 \mathrm{~h}$ of exposure time. In addi-
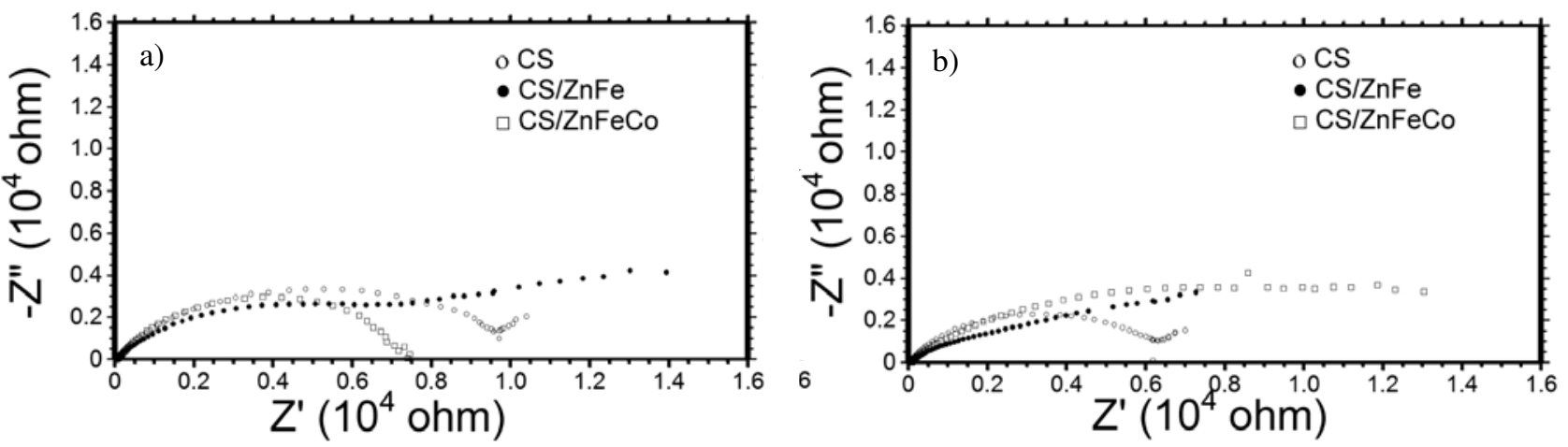

Fig. 6. The Nyquist curves of electrodes, after (a) $48 \mathrm{~h}$ and (b) $168 \mathrm{~h}$ of exposure time in $3.5 \% \mathrm{NaCl}$ solution.

Table 1. Impedance data obtained by simulation of Fig. $6 . \beta_{\mathrm{a}}=170 \mathrm{mV} \mathrm{dec}{ }^{-1}$ for bare carbon steel electrode

\begin{tabular}{|c|c|c|c|c|c|c|c|c|}
\hline Electrodes & $\mathbf{t}(\mathbf{h})$ & $E_{\text {ocp }}(V)$ & $\mathbf{R}_{p}(\mathbf{\Omega})$ & $\mathbf{R}_{\mathrm{ct}}(\Omega)$ & $R_{\mathrm{f}}(\boldsymbol{\Omega})$ & $I_{\text {corr }}(\mu \mathrm{A})$ & $\mathrm{E}(\%)$ & $\mathbf{P}(\%)$ \\
\hline \multirow{2}{*}{ Uncoated CS } & 48 & -0.669 & 9983 & - & - & 2.60 & - & - \\
\hline & 168 & -0.655 & 6691 & - & - & 3.89 & - & - \\
\hline \multirow{2}{*}{$\mathrm{CS} / \mathrm{ZnFe}$} & 48 & -0.662 & 8635 & - & - & 6.02 & - & - \\
\hline & 168 & -0.659 & 9368 & - & - & 5.55 & - & 67.66 \\
\hline \multirow{2}{*}{ CS/ZnFeCo } & 48 & -0.768 & 7396 & - & - & 7.03 & - & 35.31 \\
\hline & 168 & -0.622 & 12966 & - & - & 4.01 & 48.40 & 33.00 \\
\hline
\end{tabular}



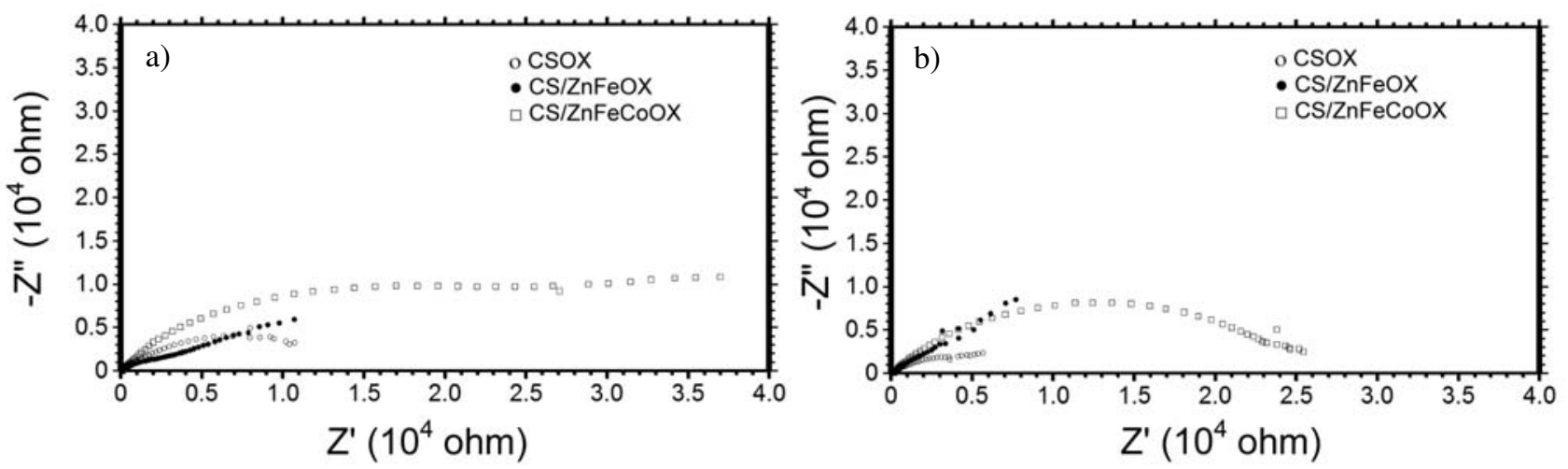

Fig. 7. The Nyquist curves of electrodes after (a) $48 \mathrm{~h}$ and (b) $168 \mathrm{~h}$ of exposure time in $3.5 \% \mathrm{NaCl}$ solution.

tion the $\mathrm{R}_{\mathrm{p}}$ values of $\mathrm{CS} / \mathrm{ZnFe}$ and $\mathrm{CS} / \mathrm{ZnFeCo}$ electrodes were significantly higher when compared with uncoated CS electrode. The increase in the $R_{p}$ values recorded for $\mathrm{CS} / \mathrm{ZnFe}$ and $\mathrm{CS} / \mathrm{ZnFeCo}$ electrodes simply indicated that alloy coatings provided an adequate physical protection to the metal between the corrosive environment and the base metal. On the other hand, $\mathrm{ZnFe}$ and $\mathrm{ZnFeCo}$ platings on carbon steel had relatively porous film structure (Table 1) and could provide poor protection to the substrate. The total diameter of depressed semicircles obtained for each electrode was equal to $R_{p}$ value. After $168 \mathrm{~h}$ of exposure time, the highest $R_{p}$ value was obtained for the CS/ZnFeCo electrode.

The Nyquist diagrams recorded for CSOX, CS/ZnFeOX and CS/ZnFeCoOX electrodes are given in Fig. 7, for 48 and $168 \mathrm{~h}$ of exposure times in $3.5 \% \mathrm{NaCl}$ solution.

In case of $\mathrm{CSOX}$ and $\mathrm{CS} / \mathrm{ZnFeOX}$ electrodes, Nyquist plots consisted of two depressed semicircles, which could not be well resolved after $48 \mathrm{~h}$ of immersion time. The first region observed in the highest frequency, which was related to the resistance against corrosion, was equal to the sum total of diffusion resistance $\left(R_{d}\right)$ and the charge transfer resistance $\left(\mathrm{R}_{\mathrm{ct}}\right)$ within pores of alloy plating and oxalate layers for $\mathrm{CS} / \mathrm{ZnFeOX}$ electrode and oxalate layer for CSOX electrode. The second semicircle for CSOX electrode was attributed to the passive layer resistance $\left(\mathrm{R}_{\mathrm{pl}}\right)$ arising from iron (II) oxalate formed on the CSOX electrode, while second semicircle for CS/ZnFe$\mathrm{OX}$ electrode was equal to the alloy coating resistance
$\left(\mathrm{R}_{\text {coat }}\right)$ and resistance of zinc oxalate and iron (II) oxalate layers. The total resistance values recorded for $\mathrm{CS} / \mathrm{ZnFe}$ CoOX electrode consisted of one depressed semicircle ranging from high frequency to low frequency at the end of $48 \mathrm{~h}$. During this time, $\mathrm{CS} / \mathrm{ZnFeCoOX}$ electrode exhibited highest corrosion performance against the attack of corrosion products such as aggressive chloride ions to carbon steel electrode. After $168 \mathrm{~h}$ of immersion time, corrosion resistance recorded for $\mathrm{CSOX}$ and $\mathrm{CS} / \mathrm{ZnFeCoOX}$ electrodes declined due to the fallen barrier property of oxalate layers and their permeability increased in the presence of chloride ions (Table 2).

Nyquist curve in longer periods, the exhibition of linear part, which denoted to the presence of Warburg impedance $\left(\mathrm{Z}_{\mathrm{w}}\right)$ for $\mathrm{CS} / \mathrm{ZnFeOX}$ electrode, could be attributed to the significant phenomena revealing a remarkable formation of new oxide layers on the $\mathrm{CS} / \mathrm{ZnFe}$ electrode at the metal/solution interface. ${ }^{35-38}$ This linear part recorded for $\mathrm{CS} / \mathrm{ZnFe}$ electrode showed a typical charge transfer process occurring under diffusion control. So, the presence of the linear part in the lower frequency region indicated that the corrosion reaction was inhibited by mass transfer limitation. This case was related to the semi-infinite diffusion of ions at the layer/electrolyte interface.

Nyquist curves obtained for CSTart, CS/ZnFeTart and $\mathrm{CS} / \mathrm{ZnFeCoTart} \mathrm{electrodes} \mathrm{after} 48 \mathrm{~h}$ exposure time in $3.5 \% \mathrm{NaCl}$ solution are given in Fig. 8. There was one depressed semicircle ranging from high frequency to low frequency region for all three electrodes. After $48 \mathrm{~h}$ of im-

Table 2. Impedance data obtained by simulation of Fig. 7. $\beta_{\mathrm{a}}=170 \mathrm{mV} \mathrm{dec}{ }^{-1}$ for bare carbon steel electrode

\begin{tabular}{lrccccccc}
\hline Electrodes & $\mathbf{t}(\mathbf{h})$ & $\mathbf{E}_{\text {ocp }}(\mathbf{V})$ & $\mathbf{R}_{\mathbf{p}}(\boldsymbol{\Omega})$ & $\mathbf{R}_{\mathrm{ct}}(\boldsymbol{\Omega})$ & $\mathbf{R}_{\mathbf{f}}(\boldsymbol{\Omega})$ & $\mathbf{I}_{\text {corr }}(\boldsymbol{\mu} \mathbf{A})$ & $\mathbf{E}(\boldsymbol{\%})$ & $\mathbf{P}(\boldsymbol{\%})$ \\
\hline $\mathbf{C S} / \mathbf{O X}$ & 48 & -0.653 & 24193 & 10094 & 14099 & -15 & 58.74 & 33.22 \\
& 168 & -0.660 & 7603 & - & - & 6.84 & 12.00 & 82.24 \\
$\mathbf{C S} / \mathbf{Z n F e / O X}$ & 48 & -0.670 & 8590 & 1934 & 6656 & 6.05 & - & 90.20 \\
& 168 & -0.741 & 337 & - & - & - & - & - \\
$\mathbf{C S} / \mathbf{Z n F e C o / O X}$ & 48 & -0.626 & 35209 & - & - & 1.48 & 78.99 & 3.07 \\
& 168 & -0.618 & 26040 & 137 & 25903 & 2.00 & 50.21 & 47.17 \\
\hline
\end{tabular}



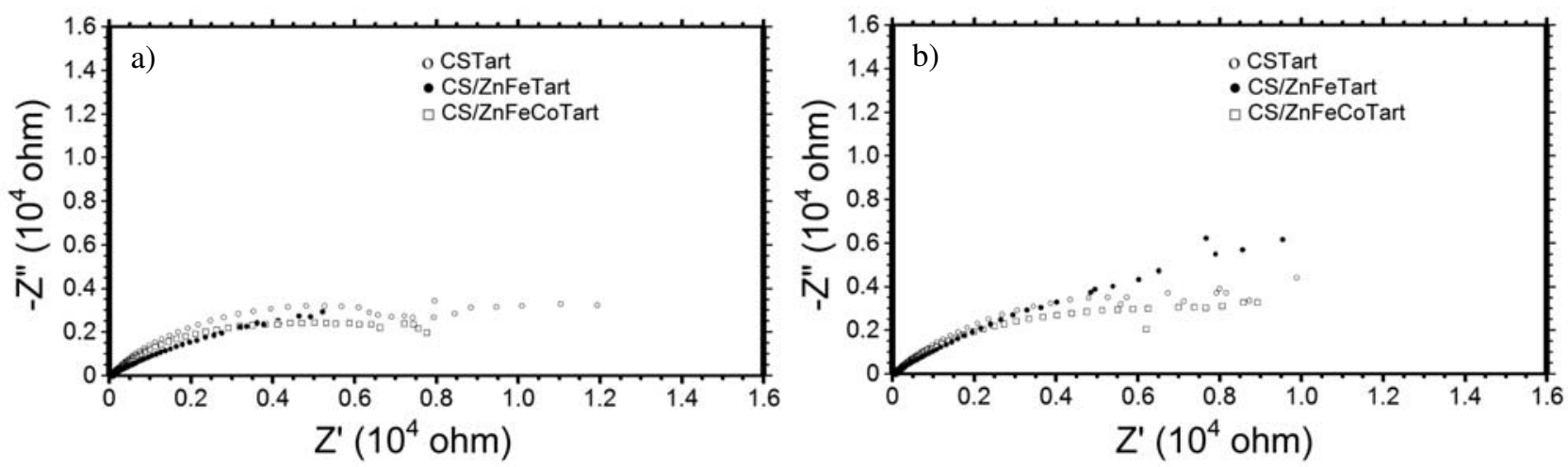

Fig. 8. The Nyquist curves of electrodes, after (a) $48 \mathrm{~h}$ and (b) $168 \mathrm{~h}$ of exposure time in $3.5 \% \mathrm{NaCl}$ solution.

mersion time, CSTart and CS/ZnFe electrodes exhibited highest corrosion resistance against the attack of corrosion products such as aggressive chloride ions to carbon steel electrode.

The exhibition of high capacitive semicircles could be related to the significant phenomena revealing a change to passive $\mathrm{CS}$ and $\mathrm{CS} / \mathrm{ZnFe}$ electrode at the metal/solution interface. On the other hand, in Table 3, the percent porosity value of $\mathrm{CS} / \mathrm{ZnFeCo}$ electrode was lowest during this period. During $168 \mathrm{~h}$ of immersion time, the $\mathrm{R}_{\mathrm{p}}$ values of all electrodes obtained in NaTart medium increased due to presence of increasing passive layers at the carbon steel surface.
The increasing values indicated that the barrier property of layers enhanced during this period and the permeability of CS and CS/ZnFe electrodes decreased in the presence of chloride ions. On the other hand, the $\mathrm{R}_{\mathrm{p}}$ value of the CSTart electrode was significantly higher than that of CSOX electrode, while these values of $\mathrm{CS} / \mathrm{ZnFeTart}$ and $\mathrm{CS} / \mathrm{ZnFe}$ CoTart electrodes were significantly lower when compared with those of $\mathrm{CS} / \mathrm{ZnFeOX}$ and $\mathrm{CS} / \mathrm{ZnFeCoOX}$ electrodes.

Open circuit potential-time and anodic polarization curves recorded for $\mathrm{CS}, \mathrm{CS} / \mathrm{ZnFe}$ and $\mathrm{CS} / \mathrm{ZnFeCo}$ electrodes in 3.5\% NaCl solution are given in Fig. 9.

The open circuit potential $\left(\mathrm{E}_{\text {ocp }}\right)$ values of the electrodes were monitored with time (Fig. 9a). Immediately

Table 3. Impedance data obtained by simulation of Fig. $8 . \beta_{\mathrm{a}}=170 \mathrm{mV} \mathrm{dec}{ }^{-1}$ for bare carbon steel electrode

\begin{tabular}{lrccccccc}
\hline Electrodes & $\mathbf{t}(\mathbf{h})$ & $\mathbf{E}_{\text {ocp }}(\mathbf{V})$ & $\mathbf{R}_{\mathbf{p}}(\boldsymbol{\Omega})$ & $\mathbf{R}_{\mathrm{ct}}(\boldsymbol{\Omega})$ & $\mathbf{R}_{\mathbf{f}}(\boldsymbol{\Omega})$ & $\mathbf{I}_{\text {corr }}(\boldsymbol{\mu} \mathbf{A})$ & $\mathbf{E}(\boldsymbol{\%})$ & $\mathbf{P}(\boldsymbol{\%})$ \\
\hline CS/Tart & 48 & -0.678 & 11122 & - & - & 4.68 & 10.24 & 79.46 \\
& 168 & -0.678 & 12599 & - & - & 4.13 & 46.89 & 38.89 \\
CS/ZnFe/Tart & 48 & -0.642 & 11302 & - & - & 4.60 & 23.60 & 58.72 \\
& 168 & -0.666 & 20032 & - & - & 2.60 & 53.23 & 42.53 \\
CS/ZnFeCo/Tart & 48 & -0.633 & 8963 & - & - & 5.80 & 17.48 & 13.26 \\
& 168 & -0.637 & 10743 & - & - & 4.84 & - & 98.50 \\
\hline
\end{tabular}
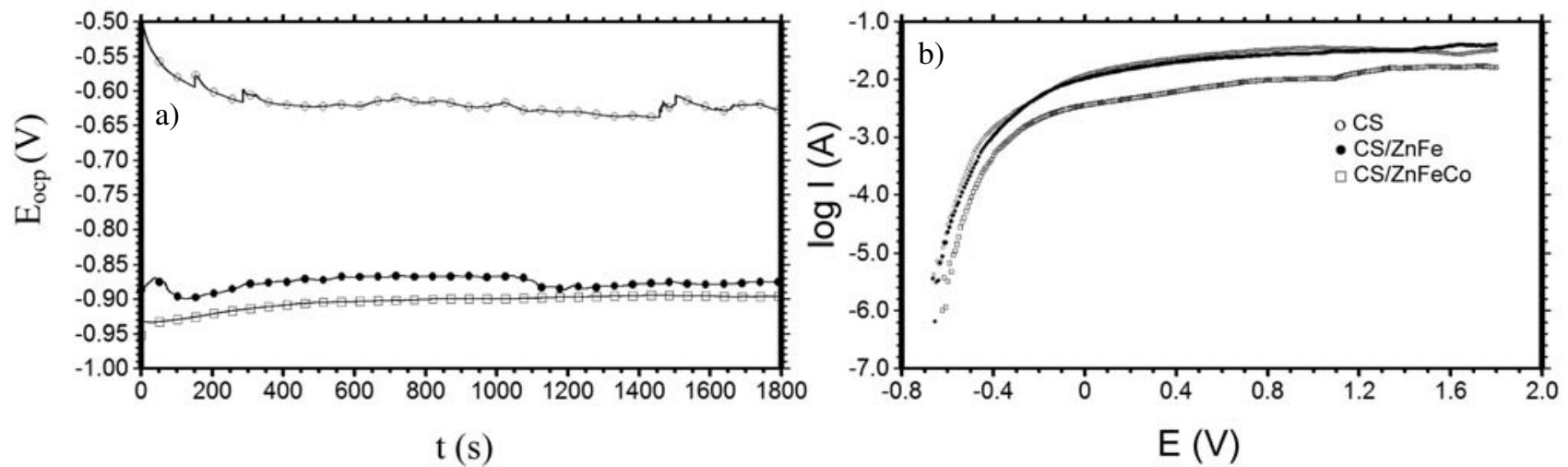

Fig. 9. The $\mathrm{E}_{\mathrm{ocp}}$ - $\mathrm{t}$ diagrams immediately after of immersion time (a) and the anodic polarization curves after $168 \mathrm{~h}$ of exposure time (b) obtained for electrodes, in $3.5 \% \mathrm{NaCl}$ solution. 
after of immersion, $\mathrm{E}_{\text {ocp }}$ values were measured as -0.493 $\mathrm{V},-0.887 \mathrm{~V}$ and $-0.952 \mathrm{~V}$ for bare CS, CS/ZnFe and $\mathrm{CS} / \mathrm{ZnFeCo}$ electrodes, respectively. $\mathrm{E}_{\text {ocp }}$ values of bare CS electrode shifted to negative potentials up to $1457 \mathrm{~s}$ of exposure time. Afterwards, $\mathrm{E}_{\text {ocp }}$ values remained negative in the active state, although it shifted to some anodic direction. There was not any possibility for passivation of the CS electrode surface under aggressive chloride ions condition, while its $\mathrm{E}_{\text {ocp }}$ value was $-0.628 \mathrm{~V}$, after $1800 \mathrm{~s}$ of immersion time. On the other hand, $\mathrm{E}_{\text {ocp }}$ values of $\mathrm{CS} / \mathrm{ZnFe}$ and $\mathrm{CS} / \mathrm{ZnFeCo}$ electrodes had more negative potential values when compared with bare CS electrode for all of immersion time. $\mathrm{E}_{\text {ocp }}$ values of the $\mathrm{CS} / \mathrm{ZnFe}$ electrode were only slightly less positive than those of $\mathrm{CS} / \mathrm{ZnFeCo}$ electrode, while their values increased in time and reached higher values. This case was attributed to remain in the passive state at sufficiently positive potentials. There was not a great difference between the $\mathrm{E}_{\text {ocp }}$ values of $\mathrm{CS} / \mathrm{ZnFe}$ and $\mathrm{CS} / \mathrm{ZnFeCo}$ electrodes, after $1800 \mathrm{~s}$. Anodic polarization tests carried out on $\mathrm{CS}, \mathrm{CS} / \mathrm{ZnFe}$ and $\mathrm{CS} / \mathrm{ZnFeCo}$ electrodes are shown in Fig. 9b. Although the $\mathrm{E}_{\text {corr }}$ value of $\mathrm{CS} / \mathrm{ZnFe}$ electrode was shifted in only slightly less noble region than that of uncoated electrode, the corrosion current $\left(\mathrm{I}_{\text {corr }}\right)$ values were almost same with that of uncoated electrode. This observation revealed that $\mathrm{ZnFe}$ alloy plating provided poor corrosion protection to $\mathrm{CS}$ electrode. On the other hand, lowest current values recorded for $\mathrm{CS} / \mathrm{ZnFeCo}$ electrode simply indicated that $\mathrm{ZnFeCo}$ alloy plating provided an adequate physical protection to the metal between the corrosive environment and underlying metal. In Table 1 , the highest $R_{p}$ value of $\mathrm{CS} / \mathrm{ZnFeCo}$ electrode supported this fact, after $168 \mathrm{~h}$ of exposure time. In addition, the positive shift in the $\mathrm{E}_{\text {corr }}$ values recorded for $\mathrm{CS} / \mathrm{ZnFeCo}$ electrode gave an evidence for passivation of the $\mathrm{CS} / \mathrm{ZnFeCo}$ electrode surface under aggressive chloride ions condition.

In order to determine different passive layers occurring on $\mathrm{ZnFe}$ and $\mathrm{ZnFeCo}$ alloy plated carbon steel and bare carbon steel electrode surfaces were polarized in aqueous $0.20 \mathrm{M}$ sodium oxalate $(\mathrm{OX})$ and $0.20 \mathrm{M}$ sodium tartrate (Tart) solutions.

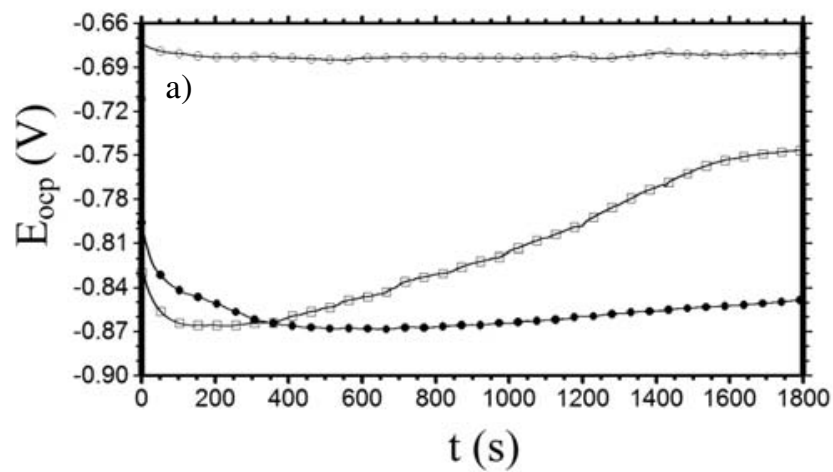

Fig. 10 shows open circuit potential-time and anodic polarization curves recorded for $\mathrm{CSOX}, \mathrm{CS} / \mathrm{ZnFeOX}$ and $\mathrm{CS} / \mathrm{ZnFeCoOX}$ electrodes in $3.5 \% \mathrm{NaCl}$ solution. In the case of uncoated CS electrode, $\mathrm{E}_{\text {ocp }}$ values remained constant close to the same potential value in $1800 \mathrm{~s}$. The almost constant value of this potential indicated the growth of the passive layer composed of iron oxides within the porous structure of zinc and iron oxalate layers. The $\mathrm{Zn}$ $\mathrm{FeOX}$ or $\mathrm{ZnFeCoOX}$ platings, which induced passivation of CS electrode was accompanied by a significant potential shift towards more noble $\mathrm{E}_{\text {ocp }}$ values. The active role of OX layer in corrosion protection was due to the interaction between the $\mathrm{ZnFe}$ or $\mathrm{ZnFeCo}$ plating and the oxalate resulting in initiation of $C S$ passivation, while $\mathrm{E}_{\text {ocp }}$ values of the $\mathrm{CS} / \mathrm{ZnFeCoOX}$ electrode were significantly nobler when compared with that of the $\mathrm{CS} / \mathrm{ZnFeOX}$ electrode after $1800 \mathrm{~s}$ of exposure time. Anodic polarization curves obtained for CSOX, CS/ZnFeOX and $\mathrm{CS} / \mathrm{ZnFeCoOX}$ electrodes after $168 \mathrm{~h}$ exposure time in $3.5 \% \mathrm{NaCl}$ solution are given in Fig. 10b. In the case of CSOX sample, corrosion potential value $\left(\mathrm{E}_{\text {corr }}\right)$ was observed to be -0.635 V. Current values increased so rapidly that there was not any possibility for passivation of the CS electrode surface under aggressive chloride ions condition. The $\mathrm{E}_{\text {corr }}$ value of $\mathrm{CS} / \mathrm{ZnFeOX}$ electrode $(-0.606 \mathrm{~V})$ shifted in the nobler region than that of CS electrode. The positive shift in the $\mathrm{E}_{\text {corr }}$ value for oxalate layer coated $\mathrm{CS} / \mathrm{ZnFeCo}$ electrode simply indicated that oxalate layer created an important passive layer on $\mathrm{ZnFeCo}$ alloy plating between the corrosive environment and the base metal. This occasion supported the idea that the current values of $\mathrm{CS} / \mathrm{ZnFeCoOX}$ electrode were significantly lower when compared with CSOX electrode. Yet, lowest current values in anodic polarization curves were observed for $\mathrm{CS} / \mathrm{ZnFeOX}$ electrode which had strongly passive layers. These results supported the $\mathrm{R}_{\mathrm{p}}$ values obtained in longer period that OX layers on $\mathrm{ZnFeCo}$ and $\mathrm{ZnFe}$ alloy depositions provided significantly better corrosion protection than that of OX layer on CS electrode. On the other hand, the anodic polarization curves of OX coated CS, CS/ZnFe and CS/ZnFeCo electrodes had lower current values when compared with

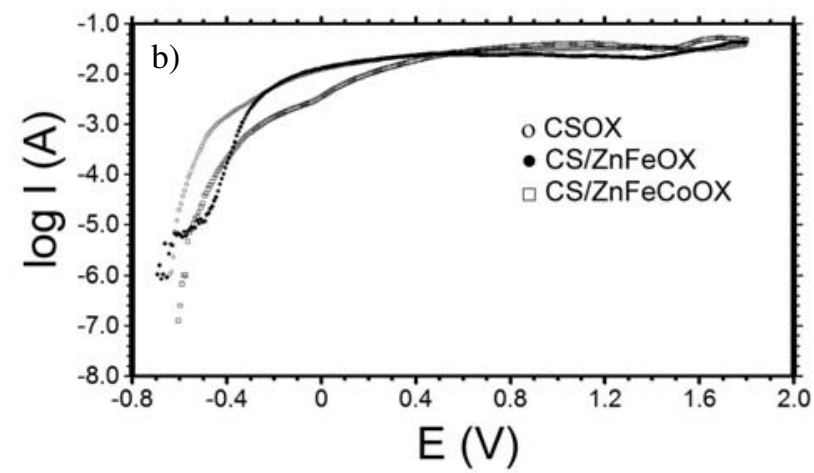

Fig. 10. The $E_{o c p}$ - $t$ diagrams immediately after of immersion time (a) and the anodic polarization curves after $168 \mathrm{~h}$ of exposure time (b) obtained for electrodes, in $3.5 \% \mathrm{NaCl}$ solution.

Ozyilmaz et al.: The Formation of Passive Layers ... 

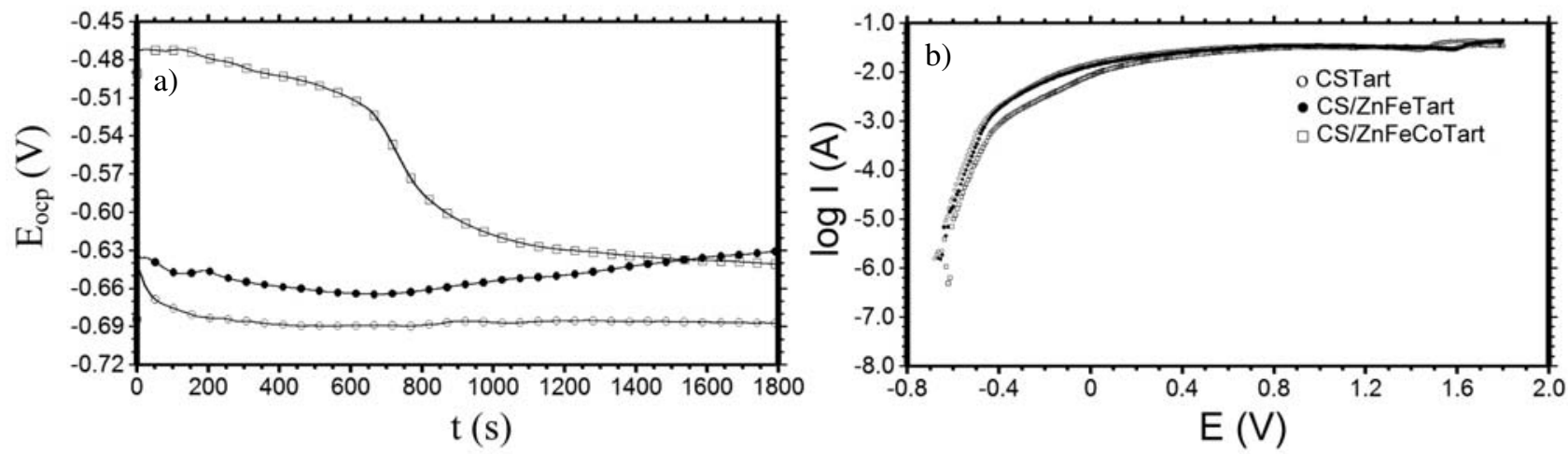

Fig. 11. The $\mathrm{E}_{\text {ocp }}-\mathrm{t}$ diagrams immediately after of immersion time (a) and the anodic polarization curves after $168 \mathrm{~h}$ of exposure time (b) obtained for electrodes, in $3.5 \% \mathrm{NaCl}$ solution.

those of oxalate free $\mathrm{CS}, \mathrm{CS} / \mathrm{ZnFe}$ and $\mathrm{CS} / \mathrm{ZnFeCo}$ electrodes.

The open circuit potential-time and anodic polarization curves of CSTart, CS/ZnFeTart and CS/ZnFeCoTart electrodes are given in Fig. 11. It is significant that the $\mathrm{E}_{\text {ocp }}$ values of $\mathrm{CS} / \mathrm{ZnFeTart}$ and $\mathrm{CS} / \mathrm{ZnFeCoTart} \mathrm{electro-}$ des were relatively nobler with respect to that of CSTart electrode, in $3.5 \% \mathrm{NaCl}$ solution. Immediately after of immersion time to $3.5 \% \mathrm{NaCl}$ solution, the surface of $\mathrm{Zn}$ $\mathrm{Fe}$ and $\mathrm{ZnFeCo}$ plating exhibited passivation according to the formation of zinc tartrate, iron tartrate and cobalt tartrate layers. At the same time, these passive layers provided a resistance against the attack of corrosion products in time, while the $\mathrm{E}_{\text {ocp }}$ values of CS/ZnFeTart and CS/ZnFeCoTart electrodes were measured as $-0.631 \mathrm{~V}$ and -0.641 $\mathrm{V}$ after $1800 \mathrm{~s}$, respectively (Fig. 11a). In Fig. 11b, anodic polarization tests were also carried out for CSTart, CS/ZnFeTart and CS/ZnFeCoTart electrodes.

After $168 \mathrm{~h}$ of immersion time, $\mathrm{E}_{\text {corr }}$ values were $-0.676 \mathrm{~V}$ for CSTart, $-0.659 \mathrm{~V}$ for CS/ZnFeTart and $-0.635 \mathrm{~V}$ for $\mathrm{CS} / \mathrm{ZnFeCoTart} \mathrm{electrodes.} \mathrm{The} \mathrm{positive}$ shift in the $\mathrm{E}_{\text {corr }}$ values for $\mathrm{CS} / \mathrm{ZnFeTart}$ and $\mathrm{CS} / \mathrm{ZnFeCo}$ Tart electrodes indicated that $\mathrm{ZnFeTart}$ and $\mathrm{ZnFeCoTart}$ coatings provided significantly better physical protection to the CS metal between the corrosive environment and the base metal. At the same time, there were much lower current values for $\mathrm{CS} / \mathrm{ZnFeCoTart} \mathrm{electrode} \mathrm{when} \mathrm{compa-}$ red with $\mathrm{CS} / \mathrm{ZnFeTart}$ electrode as well as CSTart electrode. On the other hand, $\mathrm{CS} / \mathrm{ZnFeOX}$ and $\mathrm{CS} / \mathrm{ZnFeCoOX}$ electrodes exhibited highest corrosion performance against the attack of corrosion products such as aggressive chloride ions to carbon steel electrode, when compared with $\mathrm{CS} / \mathrm{ZnFeTart}$ and $\mathrm{CS} / \mathrm{ZnFeCoTart} \mathrm{electrodes.}$

\section{Conclusions}

In this study, zinc-iron ( $\mathrm{ZnFe})$ and zinc-iron-cobalt $(\mathrm{ZnFeCo})$ alloy platings were successfully deposited on carbon steel (CS) applying $3 \mathrm{~mA}$ current value. XRD and
SEM results showed that $\mathrm{ZnFe}$ and $\mathrm{ZnFeCo}$ platings exhibited different crystal structures on carbon steel electrode. Then, passive layers contained oxalate and tartrate component were achieved electrochemically on carbon steel (CS), zinc-iron alloy plated carbon steel $(\mathrm{CS} / \mathrm{ZnFe})$ and zinciron-cobalt alloy plated carbon steel $(\mathrm{CS} / \mathrm{ZnFeCo})$ in sodium oxalate $(\mathrm{NaOX})$ and sodium tartrate (NaTart) medium, respectively. The synthesis of oxalate (OX) and tartrate (Tart) layers was obtained on CS, CS/ZnFe and $\mathrm{CS} / \mathrm{ZnFeCo}$ electrodes including an amount which would enable the passivation process. SEM images showed that the passive layers on CS, CS/ZnFe and CS/ZnFeCo electrodes exhibited different crystal structures. The corrosion performance of $\mathrm{CS}, \mathrm{CS} / \mathrm{ZnFe}$ and $\mathrm{CS} / \mathrm{ZnFeCo}$ electrodes with and without OX or Tart layer was investigated in $3.5 \% \mathrm{Na}-$ $\mathrm{Cl}$ and compared with the $\mathrm{AC}$ impedance diagrams, open circuit potential-time curves and anodic polarization curves. As a result, corrosion tests revealed that the $\mathrm{ZnFeCo}$ particles provided a significant barrier efficiency on CS layer when compared with $\mathrm{ZnFe}$ alloy plating. Furthermore, OX layers on CS, CS/ZnFe and CS/ZnFeCo electrodes exhibited better physical barrier behavior than those of Tart layers. At the same time, $\mathrm{ZnFeOX}$ and $\mathrm{ZnFeCoOX}$ coatings showed high stability and low permeability under aggressive condition and provided best anodic protection behaviour on carbon steel electrode in longer immersion periods.

\section{Acknowledgements}

The research project was funded by Technical Research Council of Turkey (TUBITAK), Project No: TBAG- (110T745) and The University of Mustafa Kemal in Turkey, Project No: 12220.

\section{References}

1.E. Kornienko, R. Ossenbrink, V. Michailov, Corrosion Science 2013, 69, 270-280. 
http://dx.doi.org/10.1016/j.corsci.2012.12.013

2. K. R. Sriraman, S. Brahimi, J. A. Szpunar, J. H. Osborne, S. Yue, Surface and Coatings Technol. 2013, 224, 126-137 http://dx.doi.org/10.1016/j.surfcoat.2013.03.010

3. Z. F. Lodhi , J. M. C. Mol, A. Hovestad, L. 't Hoen-Velterop, H. Terryn, J. H. W. de Wit, Surf. Coat. Tech., 2009, 203, 1415-1422.

http://dx.doi.org/10.1016/j.surfcoat.2008.11.019

4. A. Rafiee, K. Raeissi,; M. A. Golozar, Transactions of the Institute of Metal Finishing. 2014, 92, 115-120. http://dx.doi.org/10.1179/0020296713Z.000000000122

5. Mortaga M. Abou-Krisha, Appl. Surface Sci. 2005, 252, 1035-1048. http://dx.doi.org/10.1016/j.apsusc.2005.01.161

6. J. B. Bajat, S. Stanković, B. M. Jokić, S.I. Stevanović, Surface and Coatings Technol. 2010, 204, 2745-2753. http://dx.doi.org/10.1016/j.surfcoat.2010.02.032

7. J. Mahieu, K. De Wit, A. De Boeck, B. C. De Cooman, J. Materials Eng. and Performance. 1999, 8(5), 561-570. http://dx.doi.org/10.1007/s11665-999-0010-x

8. A. Bai, C. Hu, Electrochemistry Communications, 2003, 5, 78-82. http://dx.doi.org/10.1016/S1388-2481(02)00540-4

9. M. M. Abou-Krisha, F. H. Assaf, S.A. El-Naby, J. Coatings Technol. Research. 2009, 6(3), 391-399. http://dx.doi.org/10.1007/s11998-008-9134-4

10. S. Amirat, R. Rehamnia, M. Bordes, J. Creus, Materials and Corrosion. 2013, 64, 328-334.

http://dx.doi.org/10.1002/maco.201106290

11. M. R. El-Sharif, Y. J. Su, C. U. Chisholm, A. Watson, Corros. Sci., 1993, 35, 1259-1265.

http://dx.doi.org/10.1016/0010-938X(93)90346-I

12. A. A. O. Magalhães, I .C. P. Margarit, O. R. Mattos, J Electroanal.Chem. 2004, 572, 433-440.

13. M. H. Sohi, M. Jalali, J. Mater. Process. Tech. 2003, 138, 63-66. http://dx.doi.org/10.1016/S0924-0136(03)00050-5

14. C. K. Tan, D. J. Blackwood, Corrosion Sci. 2003, 45, 545557. http://dx.doi.org/10.1016/S0010-938X(02)00144-0

15. J. I. Martins, T. C. Reis, M. Bazzaoui,E. A. Bazzaoui and L. Martins, Corros. Sci. 2004, 46, 2361-2381. http://dx.doi.org/10.1016/j.corsci.2004.02.006

16. G. M. Spinks, A. J. Dominis, G. G. Wallace, D. E. Tallman, J. Solid State Electrochem. 2002, 6, 85-100. http://dx.doi.org/10.1007/s100080100211

17. A. T. Ozyilmaz, G. Ozyilmaz, N. Çolak, Surface and Coatings Technol. 2006, 201, 2484-2490. http://dx.doi.org/10.1016/j.surfcoat.2006.04.008

18. A. Olad, H. Rasouli, J. Appl. Polymer Sci. 2010, 115, 22212227. http://dx.doi.org/10.1002/app.31320

19. K. R. Prasad, N. Munichandraiah, Synthetic Metals. 2002, 130, 17-26. http://dx.doi.org/10.1016/S0379-6779(02)00099-1

20. M. Kraljić, Z. Mandić, Lj. Duić, Corrosion Sci. 2003, 45, 181-198.
http://dx.doi.org/10.1016/S0010-938X(02)00083-5

21. D. Sazou, C. Georgolios, J. Electroanal. Chem. 1997, 429, 81-93. http://dx.doi.org/10.1016/S0022-0728(96)05019-X

22. A. Yagan, N. O. Pekmez, A. Yýldýz, Electrochimica Acta, 2006, 51, 2949-2955. http://dx.doi.org/10.1016/j.electacta.2005.08.029

23. A. T. Ozyilmaz, M. Erbil, B. Yazýcý, Current Applied Physics. 2006, 6, 1-9. http://dx.doi.org/10.1016/j.cap.2004.06.027

24. J. L. Camalet, J. C Lacroix, S. Aeiyach, K. Chane-Ching, P. C. Lacaze, Synthetic Metals 1998, 93, 133-142. http://dx.doi.org/10.1016/S0379-6779(97)04099-X

25. J. L. Camalet, J. C. Lacroix, S. Aeiyach, K.Chane-Ching, P. C. Lacaze, J. Electroanal. Chem. 1996, 416, 179-182. http://dx.doi.org/10.1016/S0022-0728(96)01012-1

26. A. T. Ozyilmaz, A. Akdag, I. H. Karahan, G. Ozyilmaz, Progress in Organic Coatings. 2013, 76, 993-997. http://dx.doi.org/10.1016/j.porgcoat.2012.10.020

27. J. B. Bajat, S. Stanković, B. M. Jokić, J. Solid State Electrochem. 2009, 13, 755-762.

http://dx.doi.org/10.1007/s10008-008-0604-5

28. V. B. Miskovic-Stankovic, J. B. Zotovic, Z. Kacarevic-Popovic, M.D. Maksimovic, Electrochimica Acta. 1999, 44, 4269-4277. http://dx.doi.org/10.1016/S0013-4686(99)00142-5

29. J. B. Bajat, Z. Kacarevic-Popovic, V. B. Miskovic-Stankovic, M. D. Maksimovic, Progress in Organic Coatings. 2000, 39, 127-135. http://dx.doi.org/10.1016/S0300-9440(00)00127-2

30. T. Adaniya, T. Hara, M. Sagiyama, T. Homa, T. Watanabe, Plating and Surface Finishing. 1985, 72, 52-56.

31. S. Amirat, R. Rehamnia, M. Bordes, J. Creus, Mater. Corros. 2013, 64, 328-334. http://dx.doi.org/10.1002/maco.201106290

32. N. Eliaz, K. Venkatakrishna, A. Chitharanjan Hedge, Surface \& Coatings Technol. 2010, 205, 1969-1978. http://dx.doi.org/10.1016/j.surfcoat.2010.08.077

33. J. Winiarski, W. Tylus, B Szczygiel, Appl. Surface Sci. 2016, 364, 455-466. http://dx.doi.org/10.1016/j.apsusc.2015.12.183

34. N. M. Martyak, P. Mc Andrew, J. E. McCaskie, D. Dijon, Progress in Organic Coatings 2002, 45, 23-32. http://dx.doi.org/10.1016/S0300-9440(02)00070-X

35. A. T. Ozyilmaz, A. Akdag, Transactions of the Institute of Metal Finishing 2013, 91, 44-51. http://dx.doi.org/10.1179/0020296712Z.00000000063

36. A. T. Ozyilmaz, A. Akdag, Transactions of the Institute of Metal Finishing 2011, 89, 215-224. http://dx.doi.org/10.1179/174591911X13077162170188

37. G. W. Walter, Corrosion Sci. 1986, 26(9), 681-703. http://dx.doi.org/10.1016/0010-938X(86)90033-8 38. F. Mansfeld, J. Appl. Electrochem. 1995, 25, 187-202. 


\section{Povzetek}

Plasti cink-železo (Zn-Fe) in cink-železo-kobalt (Zn-Fe-Co) so bile nanešene na elektrode iz ogljikovega jekla z uporabo toka $3 \mathrm{~mA}$. Z uporabo natrijevega oksalata oziroma natrijevega tartrata kot medija, smo z elektrodepozicijo nanesli pasivne plasti oksalata oziroma tartrata na ogljikovo jeklo ter na ogljikovo jeklo s plastmi Zn-Fe in Zn-Fe-Co. SEM posnetki so pokazali različne strukture pasivnih plasti na ogljikovem jeklu in ogljikovem jeklu s Zn-Fe in Zn-Fe-Co zlitinami. Korozijski testi materiala so pokazali, da je korozijska zaščita materiala boljša v primeru plasti Zn-Fe-Co, kot pri uporabi Zn-Fe zlitine. Po drugi strani pa oksalatne plasti na elektrodah iz ogljikovega jekla in na elektrodah s plastmi $\mathrm{Zn}-\mathrm{Fe}$ in $\mathrm{Zn}-\mathrm{Fe}-\mathrm{Co}$ zlitin nudijo boljšo korozijsko zaščito kot tartratne plasti. 